\title{
Psychiatric assessments: how much is too much?
}

In the first of our patient led series to tackle mental health, this anonymous author offers valuable insights into how it feels during psychosis, and how to manage it in an emergency situation. For more information about the series, contact Rosamund Snow, patient editor, rsnow@bmj.com

Imagine groping your way up the shallow steps of a cinema auditorium, full of a powerful film that will colour the rest of your weekend. Make it a film that has got your heart pumping, made you sweat or startle. For good measure, an auditorium light has just exploded, showering one row of the audience with pieces of glass. Multiply all this 10 -fold, and it's roughly how I'm feeling now.

I am thinking fast; new fears flood in at the speed of perception. I'm noticing some things you-the interviewing doctors-do not. Yes hallucinations, some of them; fight or flight is also heightening my senses. Paranoid hypotheses are disproved and discarded, others take their place. Some will stay with me for months to come. But I don't know that there is any future. I am already passing through "stages of grief"-much as someone would if awaiting execution. This figures-I believe I am facing execution. The thought, "I'm experiencing

psychosis"- terrifying when it comes-is unavailable; it's all too new for that. It follows that all talk of "doctors," "treatment," or "admission" feels like so much persecution and deceit.

You find my thinking jumbled and confused, the quantity and register of my speech is fluctuating wildly. But I'm also hyper-attentive to language, as anyone would be in a high stakes situation (was that "talk to" or "torture"?). In an idle moment a nurse at the foot of my bed has concluded an anecdote with a hearty "I could have killed him," and perhaps she thought that was boring or inaudible, but I heard it. And I thought you wanted me to hear it, that it was in the script. (Just as I'm sure you wanted me to hear the sounds of pain just the other side of that curtain.) Because for now, you and I differ about what we think this building, this institution, is for.

In such a state, someone like me may seem beyond reassurance. But you can help-there are ways you can avoid reinforcing my fears.

First of all: duration. Sleep deprivation plus questioning is a powerful combination. Someone with an onset of acute psychosis is probably already experiencing the effects of sleep deprivation. So it doesn't help if doctors are over-cautious in making a decision, because a deferred decision equals more questioning, which means more sleeplessness and growing desperation.

In my case I was looked at by two emergency departments within 36 hours. In between the two I was put to bed at a relative's home and soon enough put my fist through a second floor window. But after treating the hand injury, the doctors in the second emergency department were still vacillating between home treatment and hospital admission. These events took place several years ago, when inpatient services were less stretched than they are today. All in all, I was interviewed by more than a dozen doctors (not counting those that followed at inpatient stage) and most of these over a 15 hour period.

A second, related factor: noise. I was told to sleep but the nurses carried out a full volume conversation among themselves throughout the night. Inevitably a particular word here or there would set off fresh panic. In my room on the ward I was woken by strip lighting every 15 minutes, by that point after many days without any real sleep. Maybe this is an unavoidable part of suicide watch, I don't know. But exposure to another patient's music (by day) surely isn't. The staff could see it was comforting for someone to play a single song on repeat. What they couldn't understand was the sinister meaning that had for me.

Third factor: the style of interviewing. While the questions may be standardly strange, the delivery can be made more or less threatening. If a doctor asks questions in a blank, detached way, it feels very frightening. A person with psychosis has not lost all ability to recognise and respond to social cues: intrusion, blankness, kindness. For example, if a doctor sits behind a desk, making eye contact but using deliberate silence to elicit my next move - and my normal civil rights hang in the balance-I will find this threatening, disorienting. It wouldn't look out of place in a police drama.

In my experience, the best communicators use calm and clarity; they treat the distressed person as a person. Paramedics are often good at this. For example, an ambulance crew applying the seat belts made this much more bearable for me by talking through the procedure-as if demonstrating it to someone in training. Granted, a psychiatric interview is not wholly transparent and doesn't try to be. But the tone of the consulting room-quasi-conversational curiosity yet unmistakeable authority-is alarming. By contrast, a psychologist who gave me cognitive behavioural therapy for psychosis (both as an inpatient and after discharge) often explained the process behind what she was doing-transparency is therapeutic.

Finally: posture and body language. A pharmacist once explained to me that my drugs, which I had spent days resisting and which had then given me uncomfortable side effects for weeks, had had little therapeutic effect and needed to be switched. He knelt down to my level while delivering this news and spoke with tangible sincerity. He was communicating that it was worth trying again with a different drug and, in effect, that he wasn't out to harm me. I felt cared for by the fact that he had taken the time to come and explain this on the ward, 
rather than over the counter at the external dispensary. I persisted with that new drug.

Competing interests: I have read and understood BMJ policy on declaration of interests and declare the following interests: none.
Cite this as: BMJ 2015;351:h3503

๑ BMJ Publishing Group Ltd 2015 


\section{The bottom line}

Consider how to make any "wait and see" in the emergency department less of an ordeal. Consider how the patient can be best insulated from noise, sights (processions of ill or injured people), and smells. Make the decision (or, if you must, postpone it), but avoid multiple interviews covering the same ground

Remain human. Inauthentic curiosity or blank expression may come across as over or under confidence (dominance, weakness, callousness) or a calculated refusal to communicate. It may provoke understandable hostility. These first impressions last and may affect a patient's recovery and willingness to engage with treatment

Find the person who calms things down. Ask other healthcare professionals-not just other doctors, but nurses and paramedics-how they communicate effectively with highly distressed people. If a patient seems to find an individual staff member worrying (even for unidentifiable reasons), consider whether there might be scope for swapping places with another person in the team to see if that helps 